\title{
More evidence that mediated priming does not occur between semantic-phonological associates
}

\author{
TIMOTHY P. MCNAMARA and STEPHANIE A. GRAY \\ Vanderbilt University, Nashville, Tennessee
}

\begin{abstract}
An experiment was conducted to test for mediated priming between semantic-phonological associates (e.g., light-damp; the mediator is lamp). Subjects made lexical decisions on single letter strings. Target words (e.g., damp) were immediately preceded by either mediated primes (e.g., light) or by unrelated primes (e.g., queen). Test lists did not contain directly related items (e.g., light-lamp). Consistent with previous findings, there was no evidence of semantic-phonological mediated priming in lexical decisions.
\end{abstract}

In a recent series of experiments, McNamara and Healy (1988) looked for mediated priming between "semantic-phonological" associates, such as light-damp and queen-sing. Note that in each pair, the two words are related by a third word (lamp and king, respectively) that is semantically related to the prime but phonologically related to the target. McNamara and Healy did not find any evidence that this kind of mediated relation facilitated lexical decisions. (There was evidence, however, of inhibitory effects, which seemed to depend on the content of the test lists.)

A problem with these experiments, however, is that two letter strings were presented on each trial. This method of presentation seems to encourage relatedness-checking strategies (McNamara \& Altarriba, 1988; Neely, Keefe, $\&$ Ross, 1989). That is, subjects use information about the semantic relation between the prime and the target to aid the decision process: when the prime and the target are related, subjects are inclined to respond "word," but when the prime and the target are unrelated, subjects are inclined to respond "nonword." Given that directly related pairs (e.g., night-dark) were included on the test lists, and that the relation between semantic-phonological associates is quite subtle, facilitative priming between these associates might have been obscured by relatednesschecking strategies (see, e.g., McNamara \& Altarriba, 1988).

The goal of the present experiment was to correct these problems. In particular, the test lists did not contain directly related items, and letter strings were presented one at a time. Previous research indicates that these characteristics eliminate relatedness-checking strategies (McNamara \& Altarriba, 1988).

\section{METHOD}

\section{Subjects}

The subjects were 200 undergraduates at Vanderbilt University. The subjects received course credit for their participation in the experiment.

Requests for reprints may be sent to Timothy P. McNamara, Department of Psychology, A \& S Psychology Building, Vanderbilt University, Nashville, TN 37240.

\section{Materials and Design}

Forty-eight mediated pairs (e.g., night-mark) were selected from the stimuli used by McNamara and Healy (1988). Pronounceable nonwords were selected from the stimuli constructed by Juola, Ward, and McNamara (1982). Items were permuted through conditions using the same procedures as those used by McNamara and Healy (see also McNamara \& Altarriba, 1988). In particular, four test lists were constructed such that (1) each target appeared in each conditon across lists, (2) no letter string appeared more than once on a test list, and (3) each list contained 12 targets preceded by mediated primes and 12 targets preceded by unrelated primes. Lists were assigned to subjects in a fixed rotation determined by the order in which the subjects participated in the experiment. Each list was seen by 50 subjects.

\section{Apparatus and Procedure}

All stimulus presentation and data collection were controlled by an IBM PC. Stimuli were displayed in lowercase letters on an Amdek 310A (amber) monitor.

The subjects received written instructions that described the task and emphasized the need for both speed and accuracy. On each trial, a single letter string was displayed, left-justified in about the center of the terminal screen. There was a 100 -msec interval between a response to a letter string and the presentation of the next letter string. The subjects pressed the " $m$ " key for words and the " $z$ "' key for nonwords. If the subjects responded incorrectly, the word "ERROR" appeared on the screen for $1 \mathrm{sec}$. There was a 1-sec interval after the error message disappeared before the next trial was presented. Test lists were divided into two 72-trial blocks. The subjects were allowed to rest between blocks.

\section{RESULTS AND DISCUSSION}

Analyses were based on means computed for each subject and each condition. Only correct responses preceded by correct responses were included in these means. Mean response latencies were $620 \mathrm{msec}$ in the mediated condition and $625 \mathrm{msec}$ in the unrelated condition $[t(199)=$ $0.98, S E D=5.31 \mathrm{msec}]$. An examination of individual subjects' data revealed that the mean in the mediated condition was less than the mean in the unrelated condition for 108 subjects $(z=1.13)$. Thus, there was no evidence that mediated priming occurred in the experiment. Given the large number of subjects and the low standard error, this null result was probably not caused by insufficient power.

The mediated relation investigated in this experiment is a "two-step" relation; that is, the primes and the tar- 
gets were separated by two associative links, or steps. Importantly, semantic two-step priming (e.g., lion-stripes) does occur in lexical decisions (McNamara \& Altarriba, 1988); there is evidence that semantic three-step priming (e.g., mane-stripes) occurs as well (McNamara \& Altarriba, 1989). These results indicate that the absence of priming between semantic-phonological associates is caused by an absence of structural connections between lexical and semantic networks (contrary to the claims of Collins \& Loftus, 1975), not by the indirectness of the relation.

\section{REFERENCES}

Collins, A. M., \& Lofrus, E. F. (1975). A spreading-activation theory of semantic processing. Psychological Review, 82, 407-428.
Juola, J. F., WARD, N. W., \& McNamara, T. P. (1982). Visual search and reading of rapid serial presentations of letter strings, words, and text. Journal of Experimental Psychology: General, 111, 208-227.

McNamara, T. P., \& Altarriba, J. (1988). Depth of spreading activation revisited: Semantic mediated priming occurs in lexical decisions. Journal of Memory \& Language, 27, 545-559.

McNamara, T. P., \& Altarriba, J. (1989). [Evidence of multiplestep mediated priming in lexical decisions.] Unpublished data.

McNamara, T. P., \& Healy, A. F. (1988). Semantic, phonological, and mediated priming in reading and lexical decisions. Journal of $E x-$ perimental Psychology: Leaming, Memory, \& Cognition, 14, 398-409. NeEly, J. H., Keefe, D. E., \& Ross, K. (1989). Semantic priming in the lexical decision task: Roles of prospective prime-generated expectancies and retrospective semantic matching. Journal of Experimental Psychology: Learning, Memory, \& Cognition, 15, 1003-1019.

(Manuscript received September 18, 1989.) 